E D I T O R I L

\title{
CINQÜENTENÁRIO DA FACULDADE DE SAÚDE PÜBLICA DA USP
}

Transcorrem neste ano algumas datas de relevante significação para a história da Faculdade de Saúde Pública. Assim é que em janeiro último ocorreu o cinquentenário do antigo Instituto de Higiene de São Paulo, órgão que foi, por assim dizer. o embrião daquilo que, vinte anos mais tarde, se transformaria na atual Faculdade. Para fixar exatamente o encadeamento dos fatos, torna-se necessário um pequeno retrospecto histórico, que apresentamos a seguir.

Com efeito, foi do núcleo inicial da Cadeira de Higiene de nossa tradicional Farculdade de Medicina que, em seu natural desenvolvimento, nasceu primeiramente o Instituto de Higiene, já com os seus cursos especializados para a formação de sanitaristas e de auxiliares técnicos, no campo da saúde pública.

Primeiro estabelecimento de ensino médico e cirúrgico que surgiu em São Paulo, a Faculdade de Medicina, sob a direção de seu fundador, o Professor Dr. Arnaldo Vieira de Carvalho, ela se iniciou em abril de 1913, com a aula inaugural proferida pelo Prof. Edmundo Xavier. Ficava a Faculdade no antigo casarão, de n." 42, na Rua Brigadeiro Tobias, no centro da cidade. Por indicação do Diretor, Dr. Arnaldo, o Governo do Estado contratou renomados médicos, do País e do Exterior, para o primeiro provimento das Cadeiras.

Dentre os especialistas estrangeiros, vieram então, da Itália, Donati, Bovero, Carini; da França, Lambert-Meyer, Brumpt; e entre outros grandes nomes internacionais, o sanitarista Samuel T. Darling, dos Estados Unidos, para prelecionar a Cadeira de Higiene e Medicina Preventiva. Em 1918, o Dr. Geraldo Horacio de Paula Souza é nomeado Assistente do Professor Darling; este, foi mais tarde substituído na cátedra por outro sanitarista norte-americano, o Prol. Samuel Smillie, continuando o Dr. Paula Souza como Assistente. Em 1922, tendo o Prof. Darling regressado para os Estados Unidos, o Prof. Paula Souza é nomeado catedrático, prosseguindo, quer no laboratório, quer no ensino e na pesquisa, a mesma elevada diretriz de seus ilustres antecessores. E é então que, em fins de 1924. da Cadeira de Higiene da Faculdade de Medicina sai o organismo que será

\section{() Instituto de Higiene}

A 26 de dezembro de 1924 o Prof. Paula Souza consegue, do Governo estadual, mediante o Decreto n. 2.018 , daquela data, a oficialização do lahoratório de Higiene, ligado à Cadeira, transformando-o no "Instituto de Higiene de São Paulo", ainda vinculado à Faculdade de Medicina. Este laboratório ocupava todo o prédio, então n. ${ }^{\circ} 45$, situado em frente à Faculdade, na rua Brigadeiro Tobias.

De modo que, após os preparativos preliminares. já a 5 de janeiro de 1925 - portanto há cinqüenta anos - começou a funcionar o Instituto de Higiene, sob a profícua direção do Prof. Geraldo H. de Paula Souza. assessorado por outro 
preclaro sanitarista, o Prof. Francisco Borges Vieira, ambos com curso de especialização na famosa Escola de Saúde Pública da John's Hopkins, de Baltimore. USA. Nesse mesmo ano de 1925, o Prof. Paula Souza apresentou à Fundação Rockefeller um plano, ambicioso para a época, de expansão das atividades do Instituto, plano elaborado conjuntamente com o Prof. Borges Vieira: solicitava, para isso, a construção de amplo prédio próprio, com todos os laboratórios e todo o aparelhamento necessários para a melhor difusão do ensino e da pesquisa, contando. inclusive, com um Centro de Saúde Modelo, para treinamento dos alunos.

Na verdade, desde 1918, a Fundação Rockefeller vinha proporcionando sua inestimável colaboração técnica e financeira à Faculdade de Medicina, sobretudo à Cadeira de Higiene. Assim sendo, e diante do elevado alcance da iniciativa, a Fundação concordou plenamente com a construção de um novo edifício próprio para o Instituto, e pôs à disposição, verba substancial para isso.

Ainda uma efeméride marcante, em 1925: a 30 de dezembro foi criado no Instituto, o Curso de Educadores Sanitários, iniciativa pioneira no gênero, em nosso País.

Diante do auxílio financeiro proporcionado pela Rockefeller, o Governo do Estado cedeu o extenso terreno situado na av. Dr. Arnaldo, esquina da Teodoro Sampaio, porque nessa vasta regiâo seriam localizados os diversos blocos do centro médico de São Paulo, num conjunto destinado à especialização médica e hospitalar - Faculdade de Medicina, Instituto "Adolfo Lutz", Hospital "Emilio Ribas" (isolamento). Instituto Médico-Legal "Oscar Freire", Instituto de Higiene e um Hospital das Clínicas, ligado à Faculdade de Medicina. A Rockefeller colaborou com o Governo na construção desse conjunto.

Entre os anos de 1930-1931 ficaram concluídas as obras do edifício do Instituto de Higiene, majestoso e imponente em forma de E, contendo sub-solo, pavimento térreo e dois andares. No sub-solo instalou-se o Centro de Saúde Modelo. que hoje tem o nome de "Prof. Geraldo H. de Paula Souza". É o prédio em que se acha a Faculdade, na Av. Dr. Arnaldo, 715, esquina da Teodoro Sampaio.

Instalado no novo prédio, o Instituto desvinculou-se da Faculdade de Medicina, a que até então pertencera; isto é, desvinculou-se parcialmente, porquanto as aulas da Cadeira de Higiene $\left(4 .^{\circ}\right.$ ano médico) continuavam a ser prelecionadas no Instituto.

Em 1934, no Governo do Dr. Armando de Salles Oliveira, foi criada a Tniversidade de São Paulo, que em seu início,congregava: a Faculdade de Filosofia, Ciências e Letras, recém-criada, a princípio instalada no edifício do Instituto de Educação "Caetano de Campos", até que se construisse o prédio da rua Maria Antônia; a Faculdade de Direito, a Escola Politécnica, a Faculdade de Medicina. a Faculdade de Medicina Veterinária, a Faculdade de Farmácia e Odontologia, a Escola "Luiz de Queiroz" de Piracicaba e, como institutos complementares da I'SP, o Instituto Médico-Legal, o Instituto de Higiene e outros mais.

Nesse mesmo ano de 1934, e por iniciativa de seus Diretores, Profs. Paula Souza e Borges Vieira, foi o Instituto de Higiene transformado em Escola de Saúde Pública, tendo em vista já sua oportuna incorporação à Universidade. Em 1938. a Escola. então pioneira no gênero, no Brasil, passou a prelecionar o Curso de especialização (hoje de Saúde Pública para graduados) para médicos sanitaristas. $E$ bem de ver que nessa Casa de ensino, o desenvolvimento didático especializado inaugurou diversos cursos para sanitaristas, dando renome de projeção nacional à Escola, a qual, por ser única no País, passou a receber, como alunos, elementos graduados procedentes das mais distantes regióes do Brasil.

E assim, aos poucos, com o prestígio crescente, até mesmo em âmbito internacional (com diversos alunos bolsistas estrangeiros) não tardou que a Escola fosse definitivamente incorporada à Universidade de São Paulo, o que ocorreu em julho de 1945, mediante o Decreto-Lei n." 14.857. assinado pelo Interventor Federal em S. Paulo. Dr. Fernando Costa. 


\section{A Faclidade de Stúde Pública}

A Escola passou então a denominar-se Faculdade de Higiene e Saúde Pública. integrando-se no conjunto dos demais estabelecimentos de nivel superior da LSP.

A instalação solene ocorreu em sessão magna da Congregação, na noite de 29 de novembro de 1945, portanto há trinta anos. Achavam-se presentes o Ministro da Educação, Prof. Raul Leitão da Cunha, o Reitor da Universidade, Prof. Jorge Americano; o Secretário de Estado da Educação e Saúde, altas autoridades rivís, militares e eclesiásticas, convidados especiais, bem como toda a Congregação. naquela noite empossada, da Faculdade.

Presidiu a solenidade o Vice-Diretor em exercício. Prof. Francisco Borges Vieira, visto que o Diretor, Prof. Geraldo de Paula Souza se achava, na ocasião, nos Estados Unidos, participando como delegado do Brasil, da Conferência Internacional da Paz, reunida em S. Francisco da Califórnia. Foi nesse conclave que o Prof. Paula Souza, juntamente com o delegado da China, apresentou o projeto, plenamente aprovado, da criação da Organização Mundial da Saúde (OMS), órgão que tantos e tão relevantes serviços vem prestando às coletividades, em esfera internacional.

A solenidade magna foi, como dissemos, às 21 horas de 29 de novembro de 1945. A primitiva Congregação da Faculdade, nessa noite empossada, era esta: Profs. Geraldo H. de Paula Souza, Diretor; F. Borges Vieira, Vice; Paulo Egydio de Oliveira Carvalho, Lucas de Assumpção, Alexandre Wancolle, Francisco Antônio Cardoso, Benjamin Alves Ribeiro, Paulo Cesar de Azevedo Antunes, Raphael de Paula Souza, José Maria Gomes, Álvaro Guimaráes Filho. Pediro A. Marcondes Machado, João Alves Meira, Vicente de Sampaio Lara, John Lane e Rubens Azzi Leal. 